\title{
Perspective
}

\section{Abuse of New Psychoactive Substances: Threats and Solutions}

\author{
Michael H Baumann*,I and Nora D Volkow ${ }^{2}$ \\ 'Designer Drug Research Unit, Intramural Research Program, National Institute on Drug Abuse, National Institutes of Health, Baltimore, MD, USA; \\ ${ }^{2}$ Office of the Director, National Institute on Drug Abuse, National Institutes of Health, Rockville, MD, USA
}

Neuropsychopharmacology (2016) 4I, 663-665; doi:I0.1038/npp.2015.260; published online I6 September 2015

\section{NPS POSE PUBLIC HEALTH RISKS}

There has been an explosive increase in the non-medical use of so-called 'designer drugs' or 'new psychoactive substances' (NPS), which are synthetic alternatives to illicit drugs of abuse (Baumann et al, 2014). NPS are easy to obtain, inexpensive, and not detected by standard toxicology screens. Products containing NPS are often given deceptive names and labeled 'not for human consumption' to circumvent laws prohibiting the sale and use of psychoactive drugs. There are well known examples of NPS that mimic most types of abused drugs-stimulants ('bath salts'), cannabinoids ('spice'), hallucinogens ('N-bombs'), and opioids ('MT-45')but the pharmacology and toxicology of these substances have not been well characterized. Although NPS can elicit subjective effects that resemble their progenitors, potential off-target sites of action are unknown and adverse medical consequences are common. Life-threatening toxidromes have been described for each type of NPS, with symptoms including agitation, hallucinations, psychosis, violent behaviors, and coma. In the United States, an alarming spike in toxic exposures and fatalities associated with abuse of synthetic cannabinoids has occurred during the past year (Trecki et al, 2015). Patients intoxicated with NPS present a significant burden to healthcare professionals, especially those involved with emergency medical care, and the longterm neuropsychiatric consequences of NPS exposure are not known.

Information available on the Internet has played a major role in facilitating the current NPS problem (Brandt et al, 2014). Neuroscience research has identified the biological substrates for most drugs of abuse, whereas the medicinal chemistry and patent literatures contain synthetic schemes for the synthesis of compounds selectively targeting the transporters and receptors mediating their psychoactive

\footnotetext{
*Correspondence: Dr MH Baumann, Designer Drug Research Unit, Intramural Research Program, National Institute on Drug Abuse, $\mathrm{NIH}$, 333 Cassell Drive, Suite 4400, Baltimore, MD 21224, USA, Tel: +443 740 2660, Fax: +443 740 224I, E-mail: mbaumann@mail.nih.gov Received II August 2015; accepted 14 August 2015; accepted article preview online 25 August 2015
}

effects. Such information can be diverted by skilled and unscrupulous individuals, or businesses, to produce NPS that are marketed and sold to consumers via the worldwide web or in brick-and-mortar shops. The vast majority of NPS are manufactured by overseas companies, and the sheer number of compounds is staggering. A recent United Nations report noted that 540 different NPS have been identified worldwide by the Office of Drugs and Crime as of 2014, and this number is expected to rise (United Nations Office of Drugs and Crime, 2015).

Unlike classic drugs of abuse, many NPS were initially developed for research purposes. In this respect, research with NPS could be considered 'dual use', which refers to research that can potentially be used for both beneficial and malicious purposes. The dual use issue is most evident for the cannabinoid NPS, as these compounds were first developed by scientists as research tools to study the endocannabinoid system. Similarly, certain cathinone analogs were first synthesized by researchers as potential medications and were subsequently diverted for abuse purposes. As the synthesis routes for most NPS are published in the literature and disseminated at scientific meetings, the argument could be made that research with these substances facilitates their diversion towards clandestine markets. On the other hand, the scientific information derived from studies with NPS offers critical knowledge of how to ameliorate potential adverse effects and manage intoxicated patients when the drugs are abused, and also offers the possibility of novel treatments for addiction and other disorders.

\section{RESPONSE STRATEGIES TO THE NPS PROBLEM}

In the United States, drug scheduling legislation has been a primary response to the NPS problem, but this approach is often ineffective (Drug Enforcement Administration, 2014). As an example, after the 2011 emergency scheduling to ban the bath salts drugs, 3,4-methylenedioxy- $N$-methcathinone (methylone) and 3,4-methylenedioxypyrovalerone (MDPV), law enforcement encounters of methylone increased more than fivefold, and this substance is still present (Figure 1). In addition, drug scheduling facilitates the appearance of 
approach is needed to deal with the rapid pace at which new
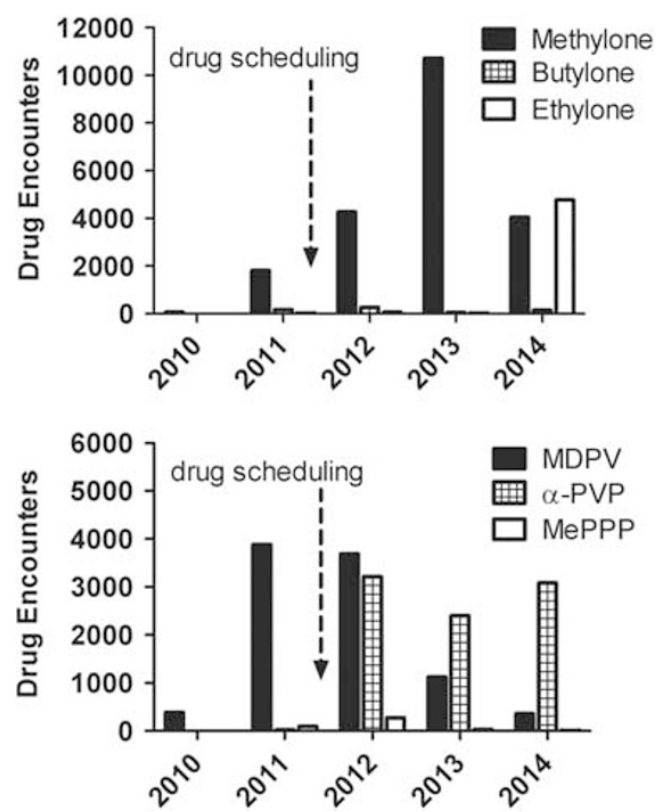

Figure I Law enforcement encounters of methylone, MDPV and selected replacement analogs from 2010 to 20I4. Data are gleaned from the National Forensic Laboratory Information System Special Report- http:// www.deadiversion.usdoj.gov/nflis/spec_rpt_CathCan_20I3.pdf and from personal communications with the DEA. Upper panel shows data for methylone and its analogs, whereas bottom panel shows data for MDPV and its analogs. The dashed arrow represents emergency scheduling of methylone and MDPV in 2011 .

new chemically distinct 'replacement' analogs, as clandestine laboratories scramble to stay one step ahead of legislative control. One such analog of MDPV, $\alpha$-pyrrolidinovalerophenone, is a popular synthetic stimulant known as 'flakka' that has wreaked havoc in Florida and other states. Finally, drug scheduling hinders the ability of scientists to obtain NPS for study, thereby impeding the very research that is needed to elucidate the effects of these substances as they emerge (Nutt et al, 2013).

Controlling the influx of NPS from overseas is a complex economic and political dilemma, especially with regard to regulating Internet commerce, but there are strategies for effectively responding to the crisis. Monitoring the emerging trends in NPS use and identifying drugs that pose risks are important first steps. The National Forensic Laboratory Information System, under the auspices of the Drug Enforcement Administration (DEA), systematically collects data from drug analyses conducted by local, state, and Federal forensic laboratories to identify psychoactive compounds. The newly established National Drug Early Warning System (NDEWS, http://ndews.org/) uses state-of-the-art methodologies to track emerging drug trends and disseminate information, but identifying the precise bioactive compounds in collected human specimens still poses challenges. Better coordination among poison control centers, emergency departments and forensic laboratories is essential. Creating a network of government-sponsored sentinel laboratories for forensic analysis of human specimens would facilitate rapid drug identification, whereas an open access national database of information about newly emerging drugs of abuse would help disseminate findings. Irrespective of the details, a coordinated multidisciplinary

drugs are appearing in the street drug marketplace.

Once specific drugs are identified, biomedical researchers are obliged to determine their pharmacology and toxicology. A number of laboratories sponsored by the National Institute on Drug Abuse (NIDA) and the DEA are already established to quickly examine basic transporter/receptor binding and behavioral effects in rodent models. However, expanded research with NPS is needed to determine: (1) their abuse liability, using animal models such as drug selfadministration and intracranial self-stimulation, which will help target treatment interventions; (2) their pharmacokinetics, bioavailability, and metabolism, which are required to develop validated forensic assays, and identify bioactive or toxic metabolites; (3) their long-term effects after acute and chronic exposure, which will help in education and prevention messages, as well as therapeutic interventions. As noted above, the scientific study of NPS is severely hampered when new drugs are placed into schedule I control. Researchers in academia and elsewhere must possess a DEA schedule I license and the infrastructure for secure drug containment in order to study even a few milligrams of the most strictly controlled substances. As new NPS emerge and are placed into schedule I control, investigators must add each drug to their DEA license via a cumbersome timeconsuming process, before any research can begin. Creating a special 'research class' schedule I license, which allows legitimate scientific investigators to study any scheduled substance, would greatly enhance the research enterprise aimed at dealing with the growing number of NPS.

Perhaps the most important step in dealing with the NPS problem is increasing public awareness of the risks posed by these drugs. The dissemination of accurate unbiased scientific information is essential as a means to decrease demand for NPS. The frequent media frenzy associated with reports of NPS has served to spread misinformation and desensitize the public to the potential dangers of these drugs. As an example, a notorious case of cannibalism in Miami during 2012 was attributed to bath salts intoxication, yet weeks later, it was reported that no NPS were identified in the perpetrator. With regard to synthetic cannabinoids, the current trend of legalizing or decriminalizing marijuana may bolster the false assumption among young people that synthetic spice compounds are safe. The most effective way to counteract such trends is to provide rigorous scientific data about NPS to the general public; informational websites, like those sponsored by NIDA and NDEWS, are essential in this endeavor.

\section{CONCLUSION}

The spread of NPS is a public health threat that may seem overwhelming in scope and complexity, but there are effective responses to the problem. It is time for a multidisciplinary coordinated effort at the national level to address this issue. Importantly, research investigations that go beyond basic pharmacology, carried out by scientist members of the ACNP and the readership of Neuropsychopharmacology, should have a pivotal role in our efforts to understand the acute and long-term biological effects of NPS. We hope that this article serves as a call to action for all 
stakeholders who are concerned and affected by this emerging drug abuse phenomenon.

\section{FUNDING AND DISCLOSURE}

Research program of $\mathrm{MHB}$ is funded by the Intramural Research Program of the National Institute on Drug Abuse, National Institutes of Health. NDV declares no conflict of interest.

\section{ACKNOWLEDGMENTS}

The authors are grateful to Eric D. Wish, $\mathrm{PhD}$, Eleanor $\mathrm{E}$ Artigiani, MA, and Jane C Maxwell, PhD for their helpful comments on this manuscript.

\section{REFERENCES}

Baumann MH, Solis E, Watterson LR, Marusich JA, Fantegrossi WE, Wiley JL (2014). Bath salts, spice and related designer drugs: the science behind the headlines. J Neurosci 34: 15150-15158.

Brandt SD, King LA, Evans-Brown M (2014). The new drug phenomenon. Drug Test Anal 6: 587-597.

Drug Enforcement Administration (2014). Special report: synthetic cannabinoids and cathinones reported in NFLIS, 2010-2013 http://www.deadiversion.usdoj.gov/nflis/spec_rpt_ CathCan_2013.pdf.

Nutt DJ, King LA, Nichols DE (2013). Effects of Schedule I drug laws on neuroscience research and treatment innovation. Nat Rev Neurosci 14: 577-585.

Trecki J, Gerona RR, Schwartz MD (2015). Synthetic cannabinoidrelated illnesses and deaths. N Engl J Med 373: 103-107.

United Nations Office of Drugs and Crime (2015). World Drug Report 2015 http://www.unodc.org/documents/wdr2015/World_ Drug_Report_2015.pdf. 